\title{
Synthesis of Poly(ester-graft-methyl methacrylate) on a Macroinitiator with Lateral Sulfonyl Chloride Groups by Atom Transfer Radical Polymerization
}

\author{
T. K. Meleshko ${ }^{a \dagger}$, A. B. Razina ${ }^{a}$, N. N. Bogorad ${ }^{a}$, M. P. Kurlykin ${ }^{a}$, A. V. Kashina ${ }^{a, *}$, \\ I. V. Gofman ${ }^{a}$, A. V. Ten'kovtsev ${ }^{a}$, and A. V. Yakimansky ${ }^{a}$ \\ ${ }^{a}$ Institute of Macromolecular Compounds, Russian Academy of Sciences, St. Petersburg, 199004 Russia \\ *e-mail: kashina.anna@mail.ru \\ Received March 15, 2021; revised April 5, 2021; accepted April 20, 2021
}

\begin{abstract}
New polymer brushes with an ester backbone and poly(methyl methacrylate) side chains are synthesized by polycondensation and polymerization methods. The initiating groups are sulfonyl chloride groups laterally attached to the polyester chain. PMMA side chains are grafted by the ATRP method according to the "grafting from" multicenter macroinitiator strategy. The conditions for the polymerization processes in a controlled mode are selected, and the ways of targeted regulation of the degree of polymerization of methacrylate side chains are determined. Using the synthesized copolymers self-supporting films are obtained, and their physical and mechanical properties are studied.
\end{abstract}

DOI: $10.1134 / \mathrm{S} 1560090421040072$

\section{INTRODUCTION}

The synthesis and research of branched polymer systems with a well-defined structure, called "polymer brushes," have been actively developing in the last decade. Among such systems, one can distinguish cylindrical polymer brushes, a special type of graft copolymers with regularly grafted narrowly dispersed side chains, which are of great practical and theoretical interest owing to their unique chemical and physical properties $[1-3]$. Such polymers are regular combshaped copolymers consisting of a backbone and narrowly dispersed side chains fairly often covalently attached to it. Much of the research in the field of macromolecular brushes focuses on the development of synthetic methods and the study of the properties of brushes with carbonchain backbones and side chains. There is relatively little data on the synthesis of brushes with a backbone of a fundamentally different nature (polyester, polyimide) $[4,5]$.

Graft copolymers with a long backbone, short side chains, and a high degree of grafting density have the unique ability to maintain their wormlike conformation [6]. It should be noted that a significant difference in the nature of the backbone and carbochain side chains determines the amphiphilicity of hybrid brushes owing to the selectivity of components with respect to solvents of different nature. This structural feature is responsible for the segregation of fragments

\footnotetext{
${ }^{\dagger}$ Deceased.
}

of the graft copolymer in solution and the formation of supramolecular structures which cannot be obtained for polymers with a different architecture [7-10]. In addition, such brushes are characterized by a significantly rarer grafting of side chains compared to carbonchain molecular brushes, which allows a much more pronounced conformational freedom of both the main and side chains. These features make hybrid brushes interesting objects not only for fundamental research but also for various practical applications [11-14]. For example, graft copolymers with a polyimide backbone and PMMA side chains were used to form nanosized homopolymer and composite Langmuir-Blodgett films which are potential candidates for use in modern electronic devices [15]. They have shown themselves as promising doping agents for industrially produced polymers in the process of creating composite polymer membranes for pervaporation and gas separation processes [16, 17]. Graft copolyimides with side chains of hydrophilic poly(methacrylic acid) (PI-graft-PMMA) were used as solubilizing nanocontainers for photodynamic theranostics agents based on cyanoporphyrazines [18, 19]. Molecular brushes with side chains of poly $(N, N$-dimethylaminoethyl methacrylate) (PI-graft-PDMAEMA) were tested as nanoreactors and stabilizing agents for the template synthesis of composite structures containing silver nanoparticles [20].

Currently, atom transfer radical polymerization (ATRP) is the most commonly used approach for the controlled synthesis of macromolecular brushes by 
Table 1. Conditions of MMA polymerization with macroinitiators I and II

\begin{tabular}{|c|c|c|c|c|c|}
\hline Initiator & $\begin{array}{l}\text { Composition of the reaction mixture } \\
\mathrm{SO}_{2} \mathrm{Cl}^{*}: \mathrm{CuCl}: \mathrm{dNbpy}: \mathrm{MMA}\end{array}$ & Solvent & $T,{ }^{\circ} \mathrm{C}$ & Time, $\mathrm{h}$ & Conversion, $\%$ \\
\hline I & $1: 1: 1.5: 200$ & Chlorobenzene & 50 & 20 & 35 \\
\hline \multirow[t]{5}{*}{ II } & $1: 2: 3: 200$ & THF & 70 & 3 & 16 \\
\hline & $1: 1: 1.5: 200$ & THF & 70 & 15 & 23 \\
\hline & $1: 1: 1.5: 200$ & Chlorobenzene & 90 & 23 & 46 \\
\hline & $1: 1: 1.5: 200$ & Chlorobenzene & 90 & 6 & 15 \\
\hline & $1: 1: 1.5: 200$ & DMF & 90 & 24 & 27 \\
\hline
\end{tabular}

* $\mathrm{SO}_{2} \mathrm{Cl}$ indicates the presence of sulfochloride groups in the macroinitiator.

polymerizing a monomer with a multicenter macroinitiator which is obtained by introducing ATRP initiating groups into its repeating units.

Methods for the synthesis of polyester(polyamide)-graft-polyoxazolines based on the use of a polyester- (polyamide)-type macroinitiator containing sulfonyl chloride groups were proposed in [21, 22].

As is known, sulfonyl chloride groups can act as initiators of atom transfer radical polymerization [23-25].

Therefore, it was of interest to test such a macroinitiator with lateral sulfonyl chloride groups for the synthesis of graft carbochain copolymers by the ATRP method.

This work is devoted to the study of this issue.

\section{EXPERIMENTAL}

The macroinitiators used were obtained according to known methods [26]. Methyl methacrylate (MMA) (99\%, Aldrich) was distilled twice in vacuum before use. $\mathrm{CuCl}(\geq 99 \%$, Aldrich) was purified from $\mathrm{Cu}(\mathrm{II})$ impurities by keeping in glacial acetic acid, filtered off, washed with methanol (reagent grade, Vekton), and dried in vacuum at $35-40^{\circ} \mathrm{C}$ for a week. THF (reagent grade, Vekton) was dried over calcium hydride and distilled. 4,4'-Dinonyl-2,2'-bipyridine (dNbpy) (97\%, Aldrich), 2-ethyl hexanoate Sn(II) ( 95\%, Aldrich), DMF, and chlorobenzene (99\%, Aldrich) were dried over calcium hydride and distilled in vacuum.

\section{Synthesis of Graft Copolymers}

A $25-\mathrm{mL}$ Schlenk flask was loaded with the weighed portions of the macroinitiator and 4,4'dinonyl-2,2'-bipyridine (Table 1). The flask was sealed with a rubber septum, evacuated for $10 \mathrm{~min}$, and filled with argon. The solvent and MMA were introduced into the flask using a syringe, and the mixture was stirred until the powder was completely dissolved. Thereafter, three freeze-pump-thaw cycles (evacuation for $15 \mathrm{~min}$ ) were carried out and the flask was filled with argon. The septum was opened, $\mathrm{CuCl}$ was added in a stream of argon, the flask was closed again with the septum, three more freeze-pump-thaw cycles (evacuation for $15 \mathrm{~min}$ ) of the reaction mixture were carried out, and the flask was filled with argon and thermostatted in an oil bath placed on a magnetic stirrer with a temperature regulator under the conditions given in Table 1.

After a given polymerization time the reaction mixture was rapidly cooled to room temperature and after opening the septum was diluted with an equal volume of THF. The resulting solution was purified from copper compounds by filtration through a column packed with $\mathrm{Al}_{2} \mathrm{O}_{3}$. The solvent was removed in vacuum, and the polymer was reprecipitated from THF in methanol. The precipitate was filtered off, washed with methanol, and dried in vacuum at $50^{\circ} \mathrm{C}$ until a constant weight was reached.

\section{Film Preparation}

Copolyimide films were obtained using molding solutions in chloroform or THF $(c=8-12 \mathrm{wt} \%)$. The films were obtained by casting prefiltered and degassed molding solutions onto a glass substrate followed by drying via evaporation of the solvent in a special chamber at an elevated temperature and conditioning in vacuum at room temperature for a week.

\section{Research Methods}

${ }^{1} \mathrm{H}$ NMR spectra were measured on a Bruker AC400 instrument (400 MHz) using solutions in deuterated chloroform. Chromatographic analysis (determination of molecular weights and polydispersity coefficients) was carried out on an Agilent-1260 Infinity chromatographic complex equipped with two columns with a PLgel MIXED-C sorbent (column size, $7.5 \times 300 \mathrm{~mm}$; particle size, $5 \mu \mathrm{m}$ ). Analysis conditions were as follows: $50^{\circ} \mathrm{C}$; isocratic elution mode; eluent, DMF containing $0.1 \mathrm{~mol} / \mathrm{L} \mathrm{LiBr}$ (flow rate, $1 \mathrm{~mL} / \mathrm{min}$ ); and a combination of refractometric and viscometric detectors with a light scattering detector (so-called "triple" detection). MW was evaluated 
without calibration. MATR FTIR spectra were measured on a Shimadzu IR Affinity-1S spectrophotometer with a resolution of $4 \mathrm{~cm}^{-1}$; the number of scans was 30 .

The mechanical characteristics of the film samples were determined at room temperature in the uniaxial tension mode using an AG-100 kN X Plus universal testing apparatus (Shimadzu Corp., Japan). Film samples with a gage size of $20 \times 2 \mathrm{~mm}$ were tested at a stretching rate of $10 \mathrm{~mm} / \mathrm{min}$. During the tests the elastic modulus $E$, strength $\sigma_{\mathrm{b}}$, and elongation at break $\varepsilon_{\mathrm{b}}$ were estimated.

\section{RESULTS AND DISCUSSION}

The chlorosulfonyl group, despite the ease of introduction into various low molecular weight and poly- mer structures, is rarely used as an initiator for cationic and radical polymerizations. As was shown earlier [26], the use of different reactivities of sulfonyl chloride and acid chloride groups under the conditions of acceptor-free polycondensation makes it possible to obtain polyesters with a lateral sulfonyl chloride group and to use them as macroinitiators of the cationic polymerization of oxazolines. In addition, the potential usefulness of such polyesters to act as macroinitiators of radical polymerization would allow the preparation of similar graft copolymers with polyacrylatetype arms.

It was found that polyesters synthesized by the polycondensation of 5-chlorosulfonylisophthalic acid dichloride with diols initiate the radical polymerization of MMA under conditions of the ATRP process.<smiles>O=C(Cl)c1cc(C(=O)Cl)cc(S(=O)(=O)Cl)c1</smiles><smiles>OCCO</smiles><smiles>[13CH3]</smiles><smiles>COC(=O)c1cc(C(=O)OC(C)(C)C)cc(S(=O)(=O)Cl)c1</smiles><smiles>CCOC(=O)c1cc(C(=O)OC(C)(C)C)cc(S(=O)(=O)Cl)c1</smiles><smiles>C=C(C)C(=O)OC</smiles><smiles>[Y]CC(C)(C(=O)OC)C(C)(C)S(=O)(=O)c1cc(C(=O)OCC)cc(C(C)(C)C(C)(C)C)c1</smiles>

$(n=3(\mathrm{I}, \mathrm{III})$ and $10(\mathrm{II}, \mathrm{IV}))$.

Therefore, we searched for the optimal conditions for obtaining graft copolymers with a polyester backbone and poly (methyl methacrylate) side chains (PEgraft-PMMA) which included varying the conditions for grafting polymerization: solvent, temperature, and catalyst amount (Table 1). Polyesters I and II differing in the length of the aliphatic spacer were used as macroinitiators. This made it possible to change the grafting density of side chains by three times. It was shown that homogeneous polymerization conditions ensured the occurrence of ATRP in THF, DMF, or chlorobenzene. The most suitable conditions for grafting PMMA side chains to polyesters I and II are a temperature of $50-90^{\circ} \mathrm{C}$ and the use of chlorobenzene as a solvent. In this case, the optimal monomer : solvent ratio was $2: 1$ if the polymerization catalyst was a $\mathrm{CuCl} / 4,4$ '-dinonyl-2,2'-bipyridine complex.
The isolated polymer products were analyzed by ${ }^{1} \mathrm{H}$ NMR, IR spectroscopy, and SEC. The monomer conversion was determined gravimetrically. The ${ }^{1} \mathrm{H}$ NMR spectrum of macroinitiator II (Fig. 1) showed signals of aromatic protons in the range of 8.5$9.0 \mathrm{ppm}$ and signals at $7.4 \mathrm{ppm}$ corresponding to two aromatic protons in the ortho position to the sulfo group. Signals of protons of the methylene groups adjacent to the carboxylate and alkoxy groups were seen at 4.4 and $3.8 \mathrm{ppm}$, respectively. Signals of the other eight methylene groups overlapped and formed two multiplets in the ranges of $1.25-1.5$ and $1.7-$ $1.9 \mathrm{ppm}$. In the ${ }^{1} \mathrm{H}$ NMR spectrum of the polymerization products obtained with macroinitiator II, signals of the PMMA block appeared; namely, the signal at 3.5-3.7 ppm belonged to $\mathrm{OCH}_{3}$ groups and the signal at $0.7-1.1 \mathrm{ppm}$ belonged to methyl groups. A low con- 

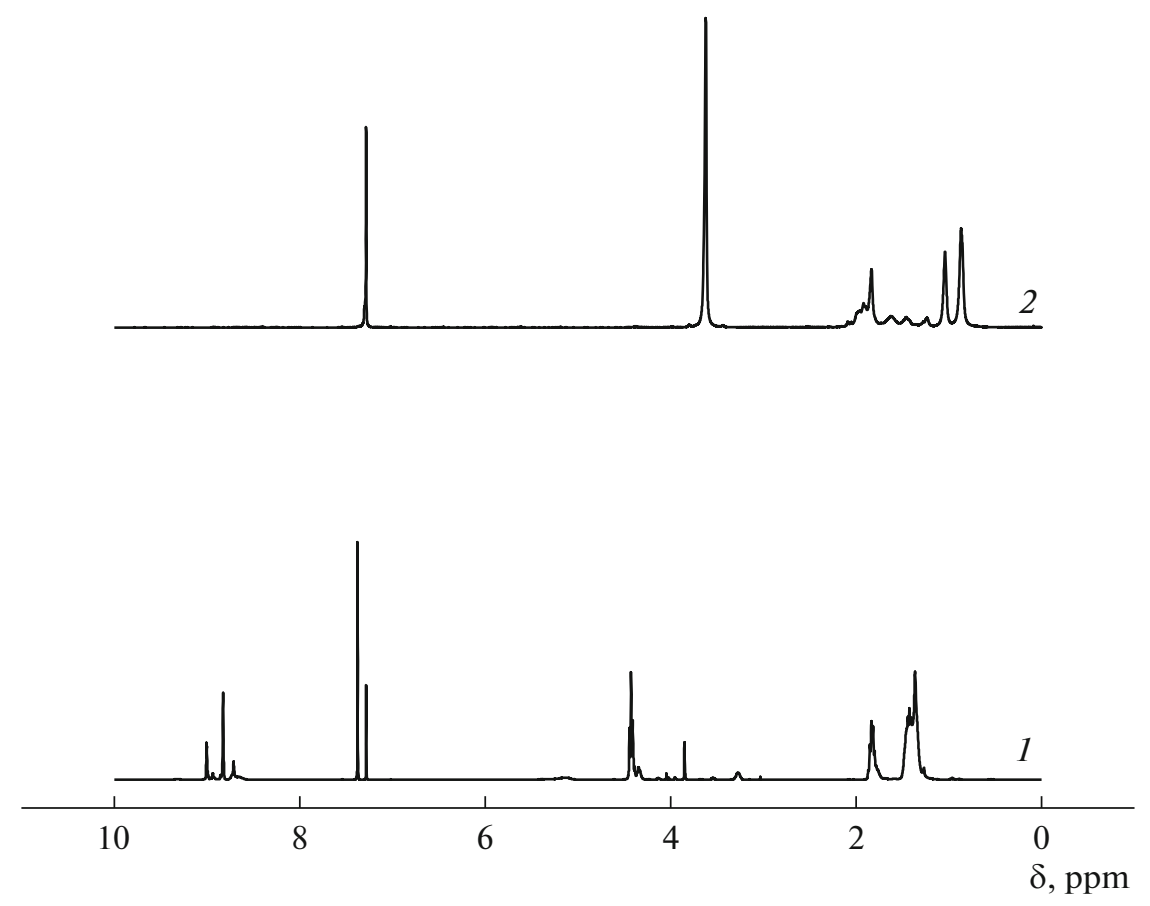

Fig. 1. ${ }^{1} \mathrm{H}$ NMR spectra of (1) macroinitiator II and (2) polymer brush IV $\left(\mathrm{CDCl}_{3}\right)$.

tent of aromatic protons of the main chain of macroinitiator II in comparison with the number of protons of PMMA side chains apparently determined the low intensity (at the noise level) of the signals of these protons in the spectrum of grafting products.

The grafting of PMMA chains to macroinitiator II in the IR spectrum was characterized by a change in the shape of bands in the range of $2800-3000 \mathrm{~cm}^{-1}$ (due to the formation of $\mathrm{CH}_{3}$ groups) and at $1730 \mathrm{~cm}^{-1}$ and the appearance of bands at $1140 \mathrm{~cm}^{-1}$ (Fig. 2). Absorption bands in the range of 1375-1340 and $1190-1160 \mathrm{~cm}^{-1}$ corresponding to asymmetric and symmetric stretching vibrations of the $\mathrm{SO}_{2}$ group which exist in the IR spectrum of the macroinitiator are also almost invisible in the spectrum apparently owing to the low relative content of sulfo groups in the final product.

Table 2 shows the molecular weight characteristics of macroinitiators I and II and the products of MMA polymerization obtained in their presence in the three above-mentioned solvents. According to the SEC data, the products obtained in THF and DMF have multimodal chromatograms, which indicates that a mixture of polymers was obtained. For example, when polymerization was carried out in DMF, the chromatogram of the product had two separate peaks (Fig. 3, curve 2). The molecular weights corresponding to these peaks are given in Table 2. A higher molecular weight peak is obviously related to the graft copolymer, the MW of which is higher than the MW of the initiator. The low molecular weight peak correspond- ing to the product with a molecular weight lower than that of the initiator can be attributed to the linear homopolymer PMMA formed via chain transfer to the monomer in a polar DMF, since this product is not detected under UV irradiation in the absorption region of aromatic polyester fragments. The chromatograms of the products obtained in chlorobenzene had a symmetrical unimodal shape. The MWs of these products significantly exceeded the MWs of the corresponding initiators (Table 2).

Polymers I and II were subjected to hydrolysis under conditions that ensure complete decomposition of the ester chain [21]. The SEC analysis of the obtained PMMA homopolymers, which are grafted side chains of the initial graft copolymers, showed that their molecular weight was $30 \times 10^{3}$ for copolymer I and $10 \times 10^{3}$ for copolymer II; these values correspond to grafting densities of 25 and $50 \%$.

The graft copolymers were white powders, readily soluble in most organic solvents. Transparent self-supporting films of copolymers with a thickness of 30$50 \mu \mathrm{m}$ were obtained by casting THF or chloroform solutions on a glass substrate. It should be noted that the initial polyesters and homo-PMMA corresponding to chain components of IV are not capable of forming such thin self-supporting films. PMMA forms films detachable without destruction from the substrate at a substantially greater thickness (about $100 \mu \mathrm{m})$. The mechanical characteristics of films of samples III and IV, which have the same polyester backbone but differ in the length of the PMMA side chains, are given in Table 3 . As can be seen, the 


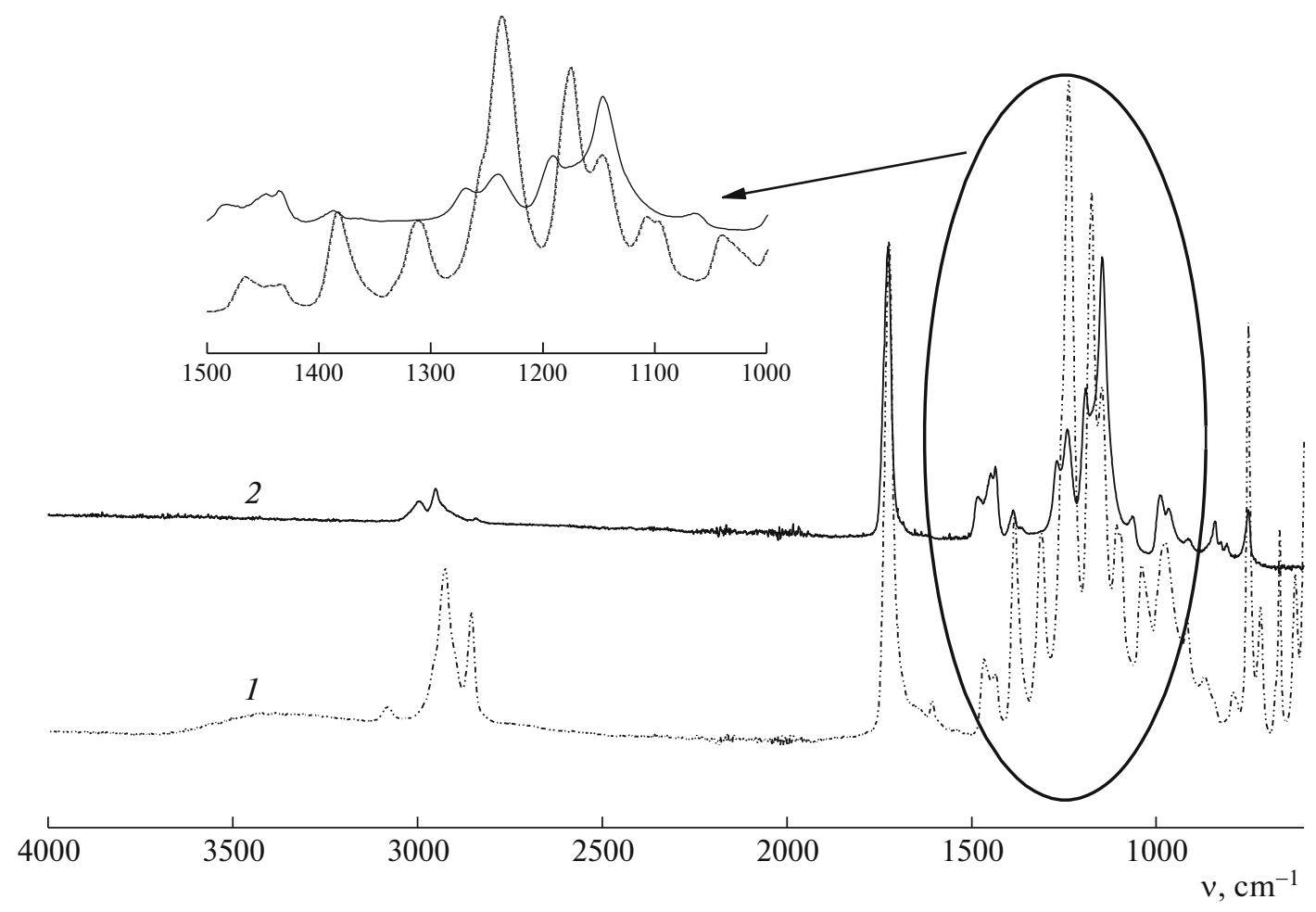

Fig. 2. IR spectra of (1) macroinitiator II and (2) polymer brush IV.

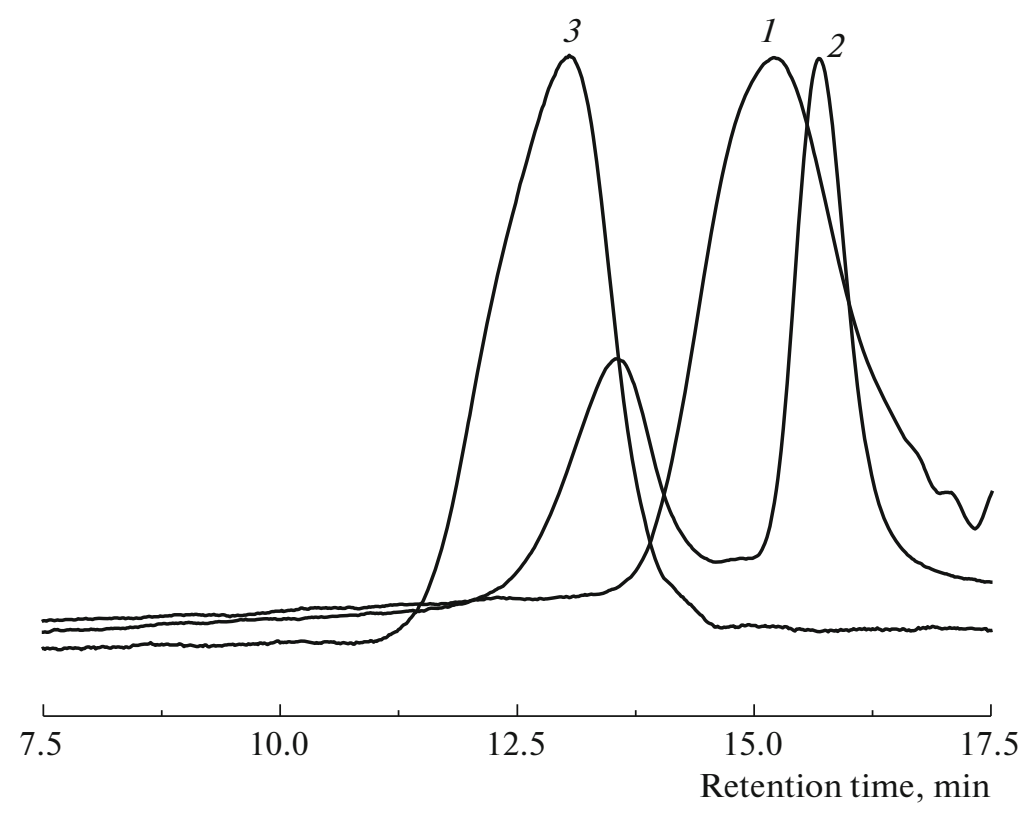

Fig. 3. Chromatograms of (1) multicenter macroinitiator II and ATRP products obtained in (2) DMF and (3) chlorobenzene.

mechanical characteristics of the films insignificantly depend on the length of side chains. The films have low values of the elongation at break $\left(\varepsilon_{\mathrm{b}}\right.$ is at the boundary of the brittle fracture region). This level of mechanical characteristics is typical of homo-PMMA films $\left(\sigma_{\mathrm{b}}=20-30 \mathrm{MPa}, \varepsilon_{\mathrm{b}}=1.5-3.0 \%, E=2.0-\right.$ $2.4 \mathrm{GPa})$, which are much thicker.

\section{CONCLUSIONS}

Using polyester-type macroinitiators containing lateral sulfonyl groups, a series of polyester-graftPMMA was obtained under ATRP conditions. The influence of temperature, solvent, and other process parameters on polymerization was determined. It was 
Table 2. Molecular weight characteristics of initiators I and II and polymerization products obtained in their presence under ATRP* conditions

\begin{tabular}{|c|c|c|c|c|c|c|c|c|}
\hline \multirow[b]{2}{*}{ Initiator } & \multirow[b]{2}{*}{$M_{\mathrm{n}} \times 10^{-3}$} & \multirow[b]{2}{*}{ 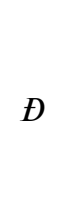 } & \multirow{2}{*}{$\begin{array}{l}\text { Degree of } \\
\text { polymerization of } \\
\text { side groups } \\
\text { calculated from } \\
\text { conversion }\end{array}$} & \multirow[b]{2}{*}{ Solvent } & \multicolumn{4}{|c|}{ ATRP product } \\
\hline & & & & & Peak & $M_{\mathrm{n}} \times 10^{-3}$ & 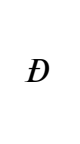 & Peak ratio \\
\hline I & 19.8 & 1.6 & 73 & Chlorobenzene & 1 & 167 & 1.24 & - \\
\hline II & 18.8 & 1.6 & 50 & Chlorobenzene & 1 & 273 & 1.7 & - \\
\hline & & & & Chlorobenzene & 1 & 435 & 1.95 & - \\
\hline & & & & DMF & 1 & 85.7 & 1.46 & 65 \\
\hline & & & & DMF & 2 & 4.5 & 1.57 & 34 \\
\hline & & & & THF & 1 & 196 & 1.7 & 43 \\
\hline & & & & THF & 2 & 16.5 & 1.03 & 57 \\
\hline
\end{tabular}

* Molar ratio of $\mathrm{SO}_{2} \mathrm{Cl}: \mathrm{CuCl}: \mathrm{dNbpy}: \mathrm{MMA}=1: 1: 1.5: 200$.

Table 3. Mechanical properties of films based on III and IV

\begin{tabular}{c|c|c|c|c|c}
\hline Initiator & Solvent & Thickness, $\mu \mathrm{m}$ & $E, \mathrm{GPa}$ & $\sigma_{\mathrm{b}}, \mathrm{MPa}$ & $\varepsilon_{\mathrm{b}}, \%$ \\
\hline I & Chloroform & 35 & $2.12 \pm 0.11$ & $49 \pm 3$ & $5.4 \pm 0.4$ \\
II & THF & 50 & $1.76 \pm 0.22$ & $38 \pm 4$ & $4.9 \pm 0.4$ \\
& Chloroform & 29 & $2.70 \pm 0.17$ & $41 \pm 4$ & $3.9 \pm 0.4$ \\
& THF & 38 & $2.21 \pm 0.09$ & $26 \pm 2$ & $2.5 \pm 0.2$ \\
\hline
\end{tabular}

shown that, when macroinitiators of the sulfonyl chloride type are used, chlorobenzene serves as an optimal solvent. Using the synthesized copolymers, self-supporting films were obtained, and their physical and mechanical properties were studied.

\section{FUNDING}

This work was supported by a grant from the Government of the Russian Federation for the state support of scientific research conducted under the guidance of leading scientists (contract no. 14.W03.31.0022).

\section{OPEN ACCESS}

This article is licensed under a Creative Commons Attribution 4.0 International License, which permits use, sharing, adaptation, distribution and reproduction in any medium or format, as long as you give appropriate credit to the original author(s) and the source, provide a link to the Creative Commons license, and indicate if changes were made. The images or other third party material in this article are included in the article's Creative Commons license, unless indicated otherwise in a credit line to the material. If material is not included in the article's Creative Commons license and your intended use is not permitted by statutory regulation or exceeds the permitted use, you will need to obtain permission directly from the copyright holder. To view a copy of this license, visit http://creativecommons.org/licenses/by/4.0/.

\section{REFERENCES}

1. Polymer Brushes, Ed. by R. C. Advincula, W. J. Brittain, K. C. Caster, and J. Rühe (Wiley, Weinheim, 2004).

2. M. Zhang and A. H. E. Müller, J. Polym. Sci., Part A: Polym. Chem. 43, 3461 (2005).

3. H. Lee, J. Pietrasik, S. S. Sheiko, and K. Matyjaszewski, Prog. Polym. Sci. 35, 24 (2010).

4. G. Yilmaz, H. Toiserkani, D. O. Demirkol, S. Sakarya, S. Timur, Y. Yagci, and L. Torun, J. Polym. Sci., Part A: Polym. Chem. 49, 110 (2011).

5. G. D. Fu, E. T. Kang, K. G. Neoh, C. C. Lin, and D. J. Liaw, Macromolecules 38, 7593 (2005).

6. S. S. Sheiko, B. S. Sumerlin, and K. Matyjaszewski, Prog. Polym. Sci. 33, 759 (2008).

7. M. Zhang, T. Breinerb, H. Moria, and A. H. E. Müller, Polymer 44, 1449 (2003).

8. Z. Zheng, A. Daniel, W. Yu, B. Weber, J. Ling, and A. H. E. Müller, Chem. Mater. 25, 4585 (2013).

9. S. Y. Yu-Su, S. S. Sheiko, H. Lee, W. Jakubowski, A. Nese, K. Matyjaszewski, D. Anokhin, and A. Ivanov, Macromolecules 42, 9008 (2009).

10. I. Muljajew, C. Weber, I. Nischang, and U. S. Schubert, Materials 11, 528 (2018). 
11. Sh. Nakagawa and N. Yoshie, Macromolecules 53, 8131 (2020).

12. Y. Higaki, M. Kobayashi, T. Hirai, and A. Takahara, Polymer 50, 101 (2018).

13. R. Mincheva, L. Jasmani, T. Josse, Y. Paint, J.-M. Raquez, P. Gerbaux, S. Eyley, W. Thielemans, and P. Dubois, Biomacromolecules 17, 3048 (2016).

14. B. Lepoittevin, L. Costa, S. Pardoue, D. Dragoe, S. Mazerat, and P. Roger, J. Polym. Sci., Part A: Polym. Chem. 54, 2689 (2016).

15. M. V. Lomova, I. V. Ivanov, S. V. German, T. K. Meleshko, A. M. Pavlov, O. A. Inozemtseva, M. N. Antipina, A. V. Yakimansky, G. B. Sukhorukov, and D. A. Gorin, J. Polym. Res. 22, 202 (2015).

16. N. S. Tian, T. K. Meleshko, G. A. Polotskaya, I. V. Gofman, A. V. Kashina, N. V. Kukarkina, E. N. Vlasova, Z. F. Zoolshoev, and A. V. Yakimansky, Polym. Eng. Sci. 60, 481 (2020).

17. N. S. Tian, T. K. Meleshko, G. A. Polotskaya, A. V. Kashina, I. V. Gofman, Z. F. Zoolshoev, V. K. Lavrentyev, Z. Pientka, and A. V. Yakimansky, J. Appl. Polym. Sci. 137, 49543 (2020).

18. N. Yu. Shilyagina, N. N. Peskova, S. A. Lermontova, A. A. Brilkina, V. A. Vodeneev, A. V. Yakimansky,
L. G. Klapshina, and I. V. Balalaeva, J. Biophotonics 10, 1189 (2017).

19. A. R. Ibragimova, A. B. Mirgorodskaya, E. A. Vasilieva, E. I. Khairutdinova, T. K. Meleshko, I. V. Ivanov, A. V. Yakimansky, I. R. Nizameev, M. K. Kadirov, and L. Y. Zakharova, Colloids Surf., A 526, 20 (2017).

20. T. K. Meleshko, A. S. Ivanova, A. V. Kashina, I. V. Ivanov, T. N. Nekrasova, N. V. Zakharova, A. P. Filippov, and A. V. Yakimansky, Polym. Sci., Ser. B 59, 674 (2017).

21. A. N. Blokhin, A. B. Razina, M. P. Kurlykin, A. V. Kashina, and A. V. Tenkovtsev, Mendeleev Commun. 30, 799 (2020).

22. M. P. Kurlykin, M. M. Dudkina, A. V. Ten'kovtsev, Polym. Sci., Ser. B 63, 103 (2021).

23. C. Li, Y. Shi, and Z. Fu, Polym. Int. 55, 25 (2006).

24. J.-L. Wang, T. Grimaud, and K. Matyjaszewski, Macromolecules 30, 6507 (1997).

25. B. Barboiu and V. Percec, Macromolecules 34, 8626 (2001).

26. A. B. Razina and A. V. Ten'kovtsev, Polym. Sci., Ser. B 61, 589 (2019).

27. B. J. Allen, G. M. Elsea, K. P. Keller, and H. D. Kinder, Anal. Chem. 49, 741 (1977). 